\title{
THE MOISTURE EFFECT ON THE INTERNAL STRAIN OF COMPOSITE INSULATION UNDER HIGH ELECTRIC FIELDS
}

\author{
Mohammad H. Abderrazzaq \\ Electrical Power Engineering Department, \\ Hijjawi Faculty for Engineering Technology, \\ Yarmouk University, Irbid-Jordan \\ Email: abder@maktoob.com
}

\begin{abstract}
This paper describes an investigation of the internal mechanical strain in composite samples with barriers cast midway between point-plain electrodes in a polyester resin. The paper also characterizes the dependence of this strain on the amount of moisture absorbed by the sample, especially under the influence of an applied electric field. In this work, the strain was studied for composite and homogeneous samples exposed to high electric fields in both wet and dry conditions. Through this study, the difference in the strain patterns between wet and dry samples is determined and the effect of moisture, as aging element reducing the adhesion strength between the barrier and the surrounding matrix, is highlighted.
\end{abstract}

\section{INTRODUCTION}

In the last two decades, composite insulation has become more popular because of the design simplicity and the cheap manufacture. Composite insulation consists mainly of matrix resin such as polyester or epoxy, filled or reinforced by another material such as glass fibre or aluminium oxide $\left(\mathrm{Al}_{2} \mathrm{O}_{3}\right)$. The type of the filler is usually selected according to the application of these composites. Despite the variety of these composites, they are all specified by a large internal microscopic interface between the reinforcement and resin. The characteristics of this interface are likely to be different from that of the component parts. It is worth noting also that the quality of the composite depends, to $\mathrm{a}^{\prime}$ great extent, on the adhesion between the reinforcement and the resin matrix [1]. 
The compressive mechanical stress, developed in the barrier region, reflects the strength of adhesion experienced between the barrier and the resin matrix [2]. If the work of adhesion between the matrix and barrier is high, the level of compressive stress around the barrier will also be high. This significantly enhances the life of the specimen by retarding the tree growth, the progression of which through composite insulation is remarkably affected by the materials' mechanical strength parameters $[3,4]$. With the reduction in the work of adhesion, the stress is significantly reduced. Therefore, the bond strength can indicate how it is easy for the tree to grow. This fact has been confirmed by noticing an appreciable delay of tree growth in dry specimens containing barrier [6].

The aim of the present paper is to show the influence of the absorbed moisture on changing the internal mechanical strain in composite and homogeneous specimens. Meanwhile, this work will highlight the role of water absorption in reducing the mechanical strength of adhesion. To achieve these goals, an experimental approach is selected. To illustrate these relations, several types of composite samples with different barrier materials were prepared and tested. Finally, a number of images, illustrating the differences in the strain patterns between wet and dry conditions, are obtained.

\section{EXPERIMENTAL}

Specimens of composite insulation were manufactured using a polyester resin matrix (resin C) with a layer of reinforcing material cast midway between the electrodes. As reinforcing materials, glass fibre mat, aluminium oxide layer and a $1 \mathrm{~mm}$ thick glass plate were utilised alternatively in these composites. Hypodermic needles were used as the

point electrode and cast $1 \mathrm{~mm}$ away from the reinforcing layer. The distance between the earth electrode and the reinforcing layer was also $1 \mathrm{~mm}$. For wet tests the specimen was exposed to water via a cavity in its upper side, whereas the voltage was applied via a pin electrode as shown in Figure1. For comparison purposes, a number of pure polyester resin specimens were manufactured. The details of casting process are described in [2].

To inspect the mechanical strength and the adhesion properties, another set of specimens was fabricated by inserting a sheet of interfacing material within a polyester tensile test piece. The mould used to cast these specimens complied with BS 2782 with three times the thickness of those used to test homogeneous polyester. The interfacing barrier was positioned in the centre of the mould perpendicular to the direction of the tensile stress. Figure 2 shows the test specimen and the tensile testing system. From the values of the load and specimen extension, displayed on the computer screen and control panel, the mechanical stress and strain can be calculated according to the equations given in [7]. 
For more reliability, it was necessary to cast at least 24 specimens for each type of composites. Additionally, 2 sets of specimens without barrier were cast; one of pure polyester resin and the other contained $50 \%$ of the plasticising agent. To verify the role of adhesion of the reinforcing material to the matrix, a set of composites was manufactured using an oiled sheet of $\mathrm{Al}_{2} \mathrm{O}_{3}$ as reinforcing barrier.

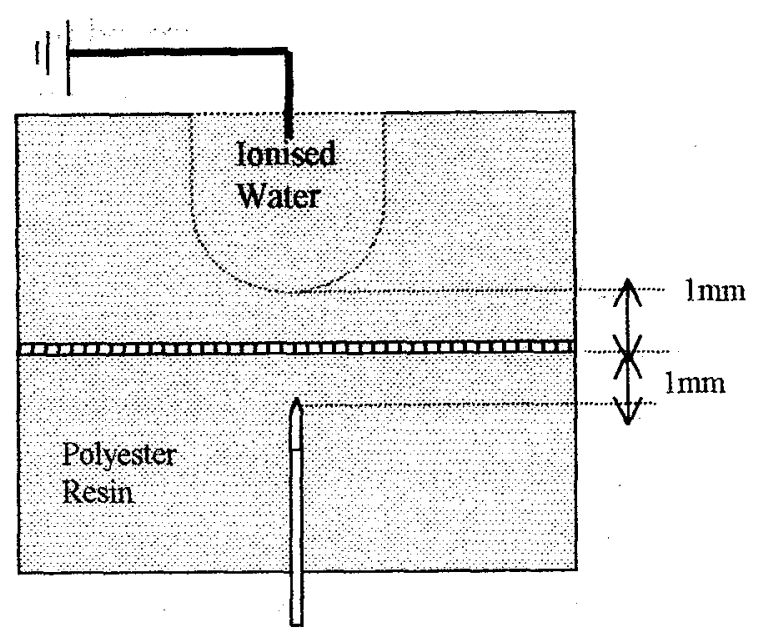

H.V Electrode

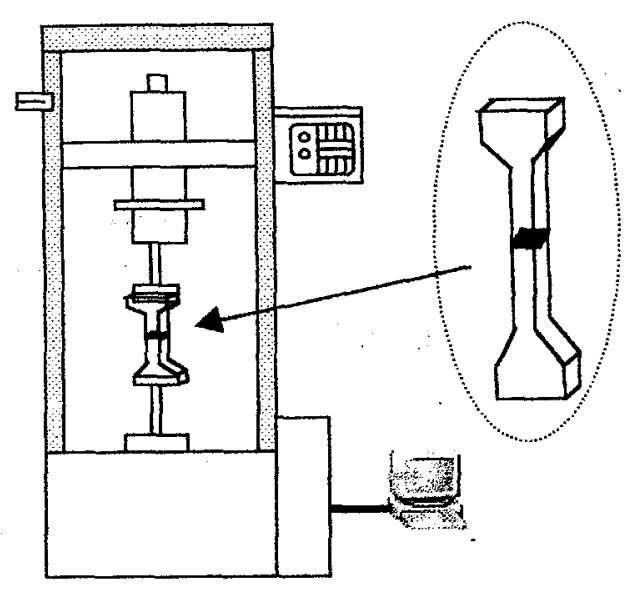

Figure 1: Composite specimen

Figure 2: Tensile testing system

The specimens arranged for the internal strain pattern tests, were divided into two test groups; wet and dry. Each group contained two identical specimens. The internal strain was inspected for both conditions; dry and wet. To all specimens, an a.c. voltage of $4 \mathrm{kV}_{\mathrm{rms}}$ was applied, for a period of 240 hours ( 10 days). The changes in the strain within the specimen, due to water absorption, were regularly inspected and documented via a series of images, using a special camera connected to an optical polariscope of cross circular type. Regarding the homogeneous resin specimens, they have been cast in two ways; double layer cast similar to that of composite specimens and single layer, where the whole block of resin was cast as one piece. The difference in strain patterns caused by these two cast procedures was examined and snapshot. To inspect the changes in the internal strain, which take place when the material is transferred from dry to wet state, a number of specimens were exposed to water after they had been already in dry conditions for more than 200 hours. The changes in the stain pattern were regularly observed and photographed. The specimens arranged for the mechanical strength testing were divided into two identical groups; one was immersed in tap water for 120 hours (5 days) to allow the water to diffuse normally in the specimen, whereas the other group was left in the normal air after being cast. Both groups were then tested for tensile strength. Concerning the plasticised specimens, the tensile test was only conducted under dry conditions. 


\section{Strain Patterns}

The presence and intensity of the internal strain within the composite specimen is affected by many variables. One of these variables is the existence of moisture around the barrier due to different absorption mechanisms. The moisture influence can be detected optically, by observing the change in the strain patterns. Two types of images were obtained for each specimen; when it was fresh and after being wet. The moisture causes some change in the colour of the strain pattern of the fresh specimen. In general, this change becomes more clear with time and, consequently, with the amount of absorbed water. Also, this change appears in the form of pale and lighter colours replacing the sharp and intensive ones. Figure 3 shows a sample of these patterns. However, if these images were presented in black and white form, the wet area is remarked by a white or close-to-white colour, whereas the strained area by a black or close-to-black colour.

To support the idea about the role of moisture in changing the strain pattern, another group of specimens was dryly tested under the same conditions. Again, strain patterns were obtained for two stages of specimen's life; when it was fresh and after being exposed to a test under dry conditions. The results had shown that the colour intensity of the strain patterns either did not differ or slightly changed. For more clarity about the responsibility of water in changing the internal strain, another type of inspection was performed. In this test, a group of already dry-tested specimens have been exposed to water for 100 hours. The reduction in the strain, when the specimen is transferred from dry to wet condition, was clear. The magnitude of this change is found to be proportional to the quantity of moisture picked up.

One can expect that the strain pattern in the pure polyester resin is different from that of composites, since there is no barrier exists in the former type. The strain appeared in the middle of the specimen is attributed to the casting procedure. Figure4 (a) shows the difference in the strain pattern in double casting specimens of pure polyester resin under fresh and wet conditions whereas Fig.4 (b) illustrates the gradual changes of strain pattern with absorbed water in specimens manufactured using single casting method.

For different specimens, the sequence of colours associated with the strain pattern could be homogeneous. This could be attributed to a number of reasons such as the type of material, curing conditions and the material construction. This phenomenon is common for all samples regardless of being composite or homogeneous. 


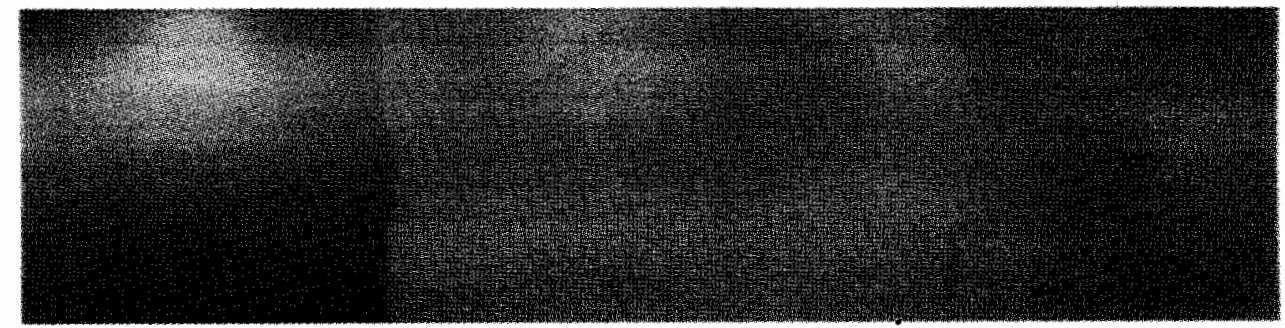

(a)

(b)

(c)

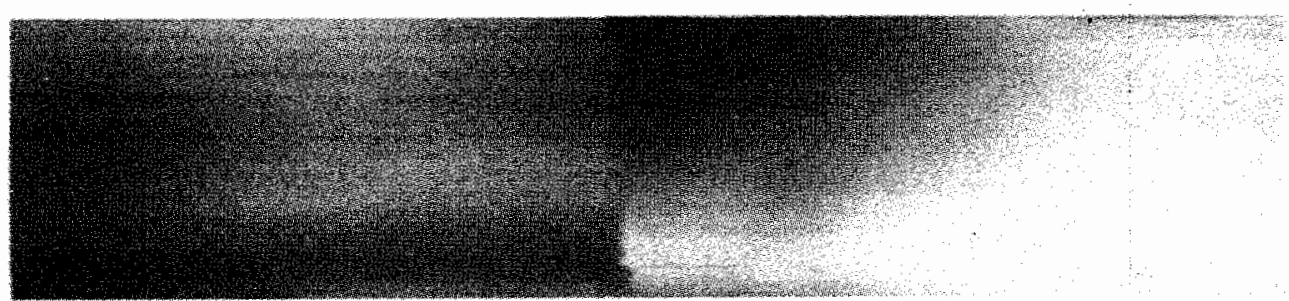

(a)

(c)

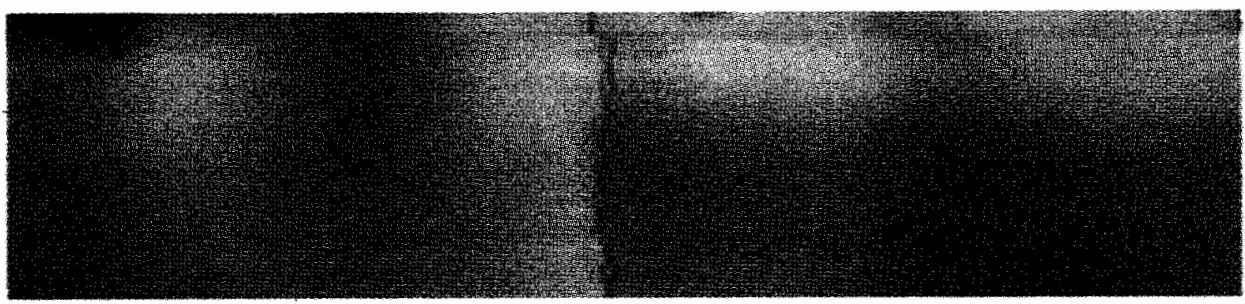

(a)

(c)

Figure 3: Strain pattern for Glass-plate, Aluminium Oxide and glass fibre composites respectively: (a) Fresh specimen, (b) dry specimen, (c) wet specimen.

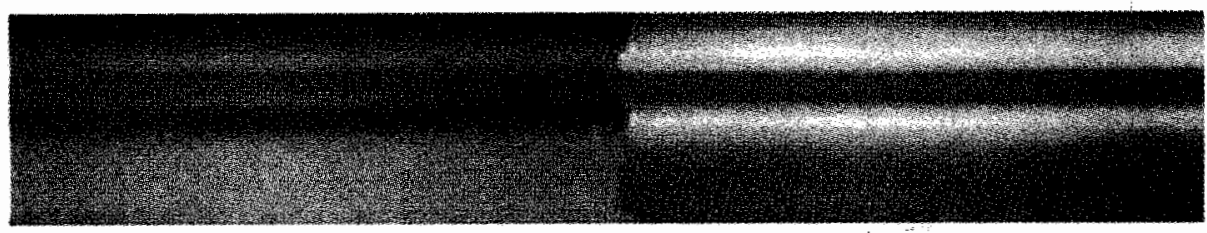

(a)

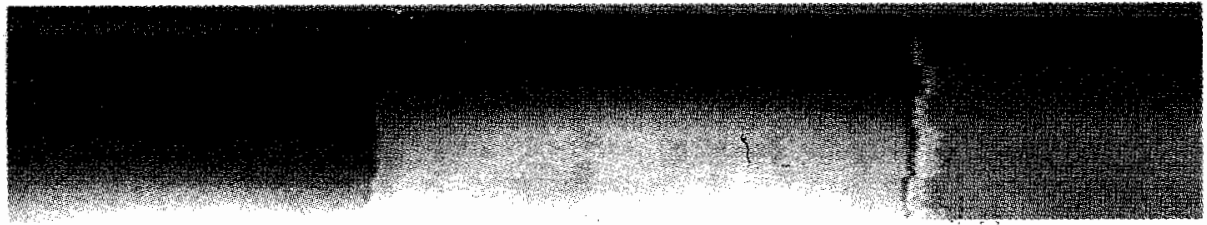

(b)

Figure 4: Strain pattern for pure resin specimens: (a) double casting fresh and wet conditions. (b) single casting fresh, wet $100 \mathrm{~h}$ and wet for $250 \mathrm{~h}$. 


\section{Mechanical Strength}

The results concerning the tensile strength test elucidate that composite specimens, which were immersed in water, have experienced a lower tensile strength compared with the dry ones. The highest tensile strength was shown by the $\mathrm{Al}_{2} \mathrm{O}_{3}$ composite, whereas the glass plate composite gave the lowest strength as illustrated in Table 1. Each value in this table represents the mean of 12 specimens tested under the same conditions.

Table 1: Tensile strength for composite and polyester specimens under different conditions.

\begin{tabular}{|l|c|c|c|c|c|}
\hline $\begin{array}{c}\text { Composite } \\
\text { Type }\end{array}$ & $\begin{array}{c}\text { Dry } \\
\text { Specimen } \\
\text { Tensile } \\
\text { Strength } \\
{[\mathrm{N}]}\end{array}$ & $\begin{array}{c}\text { Wet } \\
\text { Specimen } \\
\text { Tensile } \\
\text { Strength } \\
{[\mathrm{N}]}\end{array}$ & $\begin{array}{c}\text { Oiled } \\
\text { Specimen } \\
\text { Tensile } \\
\text { Strength } \\
{[\mathrm{N}]}\end{array}$ & $\begin{array}{c}\text { Decrease in } \\
\text { Tensile } \\
\text { Strength [\%] }\end{array}$ & $\begin{array}{c}\text { Change in } \\
\text { Extension } \\
\%\end{array}$ \\
\hline $\mathrm{Al}_{2} \mathrm{O}_{3}$ & 2200 & 1800 & 1500 & $18.18(31.8)$ & $+4(28)$ \\
\hline Glass Fibre & 640 & 350 & - & 45.3 & -3.4 \\
\hline Glass Plate & 170 & 100 & - & 41.1 & -6.7 \\
\hline $\begin{array}{l}\text { Pure } \\
\text { Polyester }\end{array}$ & 2400 & 2100 & - & 12.5 & +3.5 \\
\hline $\begin{array}{l}\text { Plasticised } \\
\text { Polyester }\end{array}$ & 1500 & - & - & $37.5^{*}$ & $558^{* *}$ \\
\hline
\end{tabular}

*In Comparison with the tensile strength of the dry polyester specimen.

** The extension was significant due to the presence of plasticiser.

\section{DISCUSSION}

The behaviour of the composite is usually affected by the behaviour of its components and the interface between these components. As being a common matrix for many composites, polyester resin is characterised by its sensitivity to moisture absorption [8] However, the initial ingress of water usually occurs through the surface of the resin. Moreover, a number of voids are formed from the solvent and water during curing processes. These voids can play an important role in decreasing the mechanical properties of composites as stated in [5]

Despite all mechanisms, proposed to explain the absorption of moisture in composites, it is easy to agree that the moisture penetrates the composite through the polyester resin. Therefore, the role of resin is not only influenced by the presence of moisture, but also 
by its ability to convey this water, especially when the resin exists in bulky form. This means that the water impact will not be limited to the resin area, but it can go to the interior of the composite and particularly to the interfacial area. The presence of electric field can accelerate this process as shown in [9]. Consequently, it is important to focus on two important factors; the water distribution mechanism and the quantity of the absorbed moisture.

It has been shown in [6], that the moisture can act as a plasticiser agent for the bulk resin, inhibiting the development of the internal mechanical stress. The water, presumably, does this by reducing the inter-chain attraction and playing the role of lubricant between chains. On the other hand, the presence of water in the interior of composite causes the expansion of composites. This expansion process can degrade the bonding between the resin and the reinforcement, which also results in decreasing the internal mechanical stress.

Internal mechanical stress is characterised by its reliance on the work of adhesion between the resin and the reinforcement material. When a sufficient quantity of water is absorbed by the specimen, the internal strain pattern starts to show some change. Although the observed strain pattern is only reflecting the effect of water in a plane perpendicular to the light beam, the changes in the colours observed, monitor the degree of the impact of water absorption on the internal strain inside the specimen.

The tensile strength measurements disclose the mechanical durability of the adhesion between the composite components. Wet specimens and those with deliberately reduced bond strength, by oiling of the barrier material, have shown a reduced tensile strength compared with dry ones. In all wet specimens, and in most dry specimens, the breakage occurred at the barrier line, emphasising the fact, that the bond is always a weak link.

\section{CONCLUSIONS}

The change in the mechanical strain in the barrier region due to water absorption has been documented as a supporting proof for the moisture effect on material properties. It was shown that water absorption could change the mechanical tensile strength of different composites by reducing the strength of the bond between the matrix and resin and by acting as plasticising agent. Finally, the assumption that the reduction in the mechanical tensile strength of composites, due to the damage of the interfacial bonds, was proved by testing composite specimens with low adhesion oiled-barriers. 
1. L.J.Broutman and R.H.Krock, "Modern Composite Materials", Addison-Wesley publishing Company, USA, 1967.

2. D.W.Auckland, S.M.F. Kabir and B.R.Varlow, "Effect of barriers on the growth of trees in solid insulation". IEE Proc. Vol. 139. pp.14-20. 1992.

3. Y.Poggi, et al, "Water Treeing as Mechanical Damage" IEEE Trans. on Elec. Ins. Vol. 25 No.6,December 1990.

4. D.W.Auckland, "Dependence of Electrical Tree Inception and Growth on Mechanical Properties", IEE Proc.A, Vol.138,No.1, Jan.1991.

5. D. Hull, "An Introduction to Composite Materials", Cambridge University Press, Cambridge, 1988.

6. M.Abderrazzaq, D.W.Auckland and B.R.Varlow, "Effect of water absorption on the growth of trees in composite insulation". IEEE, Conference on Electrical Insulation and Dielectric Phenomena, San Francisco, 1996.

7. J.C.Anderson,et al, "Material science", Chapman and Hall publisher, p205,1990.

8. Scott Bader Company, "Polyester Handbook", London, 1990.

9. D.W.Auckland, et al, "Water Absorption in Composite Dielectrics", IEEE $5^{\text {th }}$ International Conference on Conduction and Breakdown in Solid Dielectrics, LeicesterEngland, 1995. 
أثر الرطوبة على الثوتر الداخلي للعازلية الملكبة الواقعة تحت ججالات كهربائية عالية

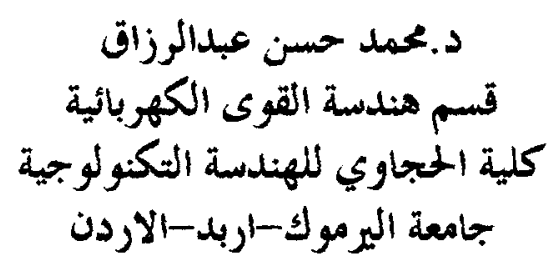

Email: abder@imaktoobcom

ملخصص البحث:

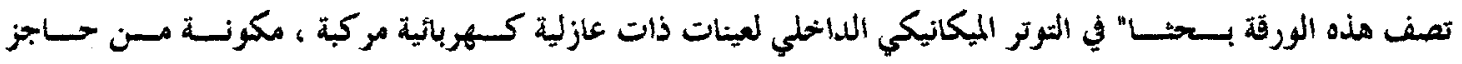

مسبوك في منتصف المسافة بين قطبين أحدهــما نقطة والأخر سطح وكلاهـــا مغموران في راتينج البولســـرين ـ كمــ

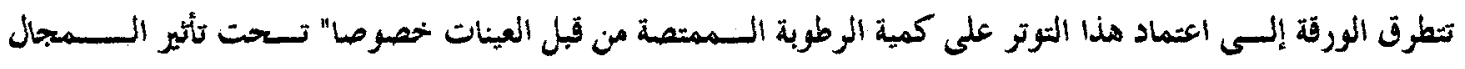

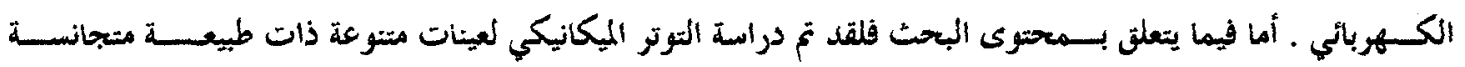

ومركبة، تسـم تعريضــها لــمجالات كهربائية عالية في ظروف جافــة ورطبة. من نحلال هذه المرأسة تع أيضا" تحديسـد

الفرق في نماذج التوتر الميكانيكي بين العينات الرطبة والجمافة و إظــهار مدى تأثير الرطوبة كعنصر تعتيق يعمل على تقليـل

ثوة الاكتصاق الميكانيكية بين الحاجز ونسيج الراتينج الغيط به . 